\title{
Editor's letter
}

Dear all,

By releasing the first issue of our $32^{\text {nd }}$ volume, we officially start a new year in Horticultura Brasileira. In 2014, declared by FAO as the International Year of Family Farming, our covers will refer to the theme, so close it is to our vegetables and condimental, medicinal and ornamental plants. We opened the year with first class art illustrating our cover (our thanks to the artist Malu Delibo, whose biography appears in this issue, at the third cover, and also to the Gallery Jacques Ardies, who gave us the right to free use) and a provocative text from researcher Maria Thereza Pedroso. Do not miss both, image and text!

As usual, in the issue that opens the year we indicate our challenges for the period. In 2014 we will focus primarily on continuing to ask for advances in the discussion of the results in the papers published in the journal. It is important that more and more our authors join the Editorial Board on this commitment. We count on all of you!

In this issue, we must also say goodbye and thanks, repeatedly, to two associate editors, colleagues of irreparably conduct and unquestionable competence, who had decisively contributed to the progress Horticultura Brasileira experienced in the last decade: Paulo Espíndola Trani, who retires in early 2014, and Wilson Sebastião Tivelli, who will be devoted entirely to the Unit for Research and Development of São Roque, APTA, now the Reference Center for Organic Agriculture of the Department of Agriculture and Food Supply of São Paulo. Trani and Tivelli, we wish you success!

See you in our next issue,

Paulo Melo, editor-in-chief 